\title{
Research on the Diversified Development of New Agricultural Management Subject
}

\author{
Dan Huang ${ }^{1, \text { a }}$ \\ ${ }^{1}$ Wuhan Donghu University, Wuhan City, Hubei Province, 430200, China \\ aemail:
}

Keywords: New Agriculture; Agricultural Management; Subject; Diversified Development

\begin{abstract}
Agriculture is a significant basic industry of China's national economy, and according to the development situation of agricultural economy in China, cultivating new agricultural management subject, and focusing on its diversified development and system supply, are important manifestations of the continuous reform of China's agricultural economic system, which also have great significance for improving sustainable development of the national economy. Based on the author's learning and practical experience, this paper first analyzed the situation of diversified development of new agricultural management subject, then put forward the diversified development strategies of the new agricultural management subject.
\end{abstract}

\section{Introduction}

New agricultural management subject is the agricultural management organization which has relatively large scale of operation, better material and equipment condition and management capability; and its labor production, resource utilization and land production rate are relatively high, which main purpose is commercial production. New agricultural management subject includes professional farming investors, family farms, farmer professional cooperatives, leading enterprises and organizations that managing agricultural services, etc. The reform and innovation of the agricultural management system are the important foundation for the construction of the new agricultural management system. It is necessary to formulate the appropriate supply system and development plan according to the actual development demand of the agricultural economy in our country, so as to effectively solve the problems existing in the agricultural management in our country, thereby improving the development of new agricultural management subject in our country rapidly.

\section{The situation of diversified development of the new agricultural management subject}

Family-run type of agricultural management subject. Under normal circumstances, the family-run type of new agricultural management subject refers to regarding the family as the main subject of agricultural production, including family farms and professional large investors, which has an important impact on promoting the development of agricultural production in our country. With the continuous improvement of China's market economy system, the total amount of rural part-time peasants is increasing, and the development speed of professional farmers is also increasing rapidly, which provides an important basis for the diversified development of new agricultural management subject. As relevant survey and data show, various rural professional farmers, growers and so on have not spent all the time and energy on the breeding and planting industries. Instead, the breeding and planting industries that they engaged have the characteristics like professional, commercialized, enlarged scale and so on, which are the important demand of China's agricultural modernization development, and have significant impact in promoting sustainable development of China's new agriculture. 
Enterprise-run type of agricultural management subject. In the situation of continuous improvement of modern agricultural management system, the main way of agricultural enterprises is the social production, which forms a division system with the farmers. And it mainly operates in agricultural business chain, and plays a great role in promoting the development of farmer market, which is an important manifestation of the modern agricultural enterprises fully playing the guiding and organizing role. With the continuous promotion of information technology and high-tech technology, improving agricultural facilities through the enterprises and companies and other forms of business can give full play to their fund, technology and other advantages, which have an important impact on improving the production efficiency of agricultural products

Cooperative operation type of agricultural management subject. In the earliest period, the peasant cooperative economy is mainly based on family contract management, such as farmer professional association, farmer technical association. According to the operation of farmer's professional cooperatives, the use of farmer cooperation can effectively solve the economic problems brought by small-scale family farmers, and on the basis of making full use of modern agricultural production technology and various funds, to achieve the intensive development of farmer production, so as to comprehensively improve the production level of our country's new agriculture. With the continuous development of rural economy and agricultural production, the new agricultural management is developing rapidly in the direction of specialization and branding. It has an important influence on satisfying the various demand of agricultural products and realizing the effective circulation and smooth marketing of agricultural products.

The relationship between the new agricultural management subject. Cooperative operation, family-run, enterprise-run and other types of operating entities have certain differences in operating mechanism, property rights and distribution relationship, and thus play different roles in the development and practice of agricultural production. Therefore, in the mode of diversified new agricultural management, the relationship between the various operating entities has the characteristics of mutual coordination, which needs to choose the appropriate business mode according to the actual situation of agricultural production, in order to better promote the orderly development of agricultural products market, finally to achieve a multiplier effect on operating results.

\section{The strategy of diversified development of the new agricultural management subject}

Fully understand the system tension of mandatory institutional changes, provide a good institutional environment for the new agricultural management subject. First, innovate rural land circular system. The development of the new agricultural management subject requires the smooth circulation of rural land. If the rural land circulation is poor, the centralization and scale-up of rural land management will be inevitably blocked, and the development of new agricultural management subject is nothing. Therefore, how to achieve the smooth circulation of rural land is an urgent issue need to be solved at present. The fundamental thought is to let rural land management rights become the right of possession, to make rural land rights more transferable, so as to help stimulate the vitality of the rural land market. Some rights attributed to the cooperative land ownership can be released and separated level by level, and ultimately make the rural land management rights more conformed to the market free flow requirements, so that the rights have more legitimacy, stability and liquidity.

Second, improve the new agricultural management subject's social service system. The social service system of the new agricultural management subject first needs the support of information service. In the rapidly changing market economy, the acquisition of information is 
essential to the market subjects. Agriculture is a weak industry, but it concerns the national economy and people's livelihood, market information services should be provided mainly by the government. Next, the need for financial services support. However, the loan services provided by bank are often not in place in reality, the enthusiasm of the loan is not high. We find the reason is the existence of many obstacles in using rural land for mortgage loan, such as rural land property rights are not clear, land mortgages are usually impossible to achieve. Given this, first we should establish the registration system of rural land property; the second is to innovate the rural land security mechanism, such as establishing the rural property mortgage financing risk funds by financing or setting up a special rural property financing guarantee company to resolve the rural land mortgage risk can be considered. Besides, the new agricultural management subject should also strengthen cooperation with scientific research institutes to obtain better technical service support.

Third, introduce support policies for new agricultural management subject. First, to encourage the development by tax preferences. Such as only impose individual income tax and business tax for the new agricultural management subject business income, etc. Second, to give certain financial subsidies, especially for grain and other important crops cultivation operation, subsidies should be directly distributed to the new agricultural management subject, so their basic interests would be guaranteed, thus maintain the enthusiasm of new agricultural management production and operation.

Fourth, improve the legislation of the new agricultural management subject. At present, China has only promulgated the "Farmers Professional Cooperative Law", and some other important new types of agricultural management subject such as family farms are still blank in legislation. We should formulate the laws and regulations to regulate other new agricultural management subject as soon as possible, so as to further improve the legislative system of the new agricultural management subject and clarify the qualification and function orientation of the new agricultural management subject.

Clarify the function orientation of new agricultural management subject, focus on the chain connection between the subject. In order to enhance the market trading capability of new agricultural management subject such as farmer professional cooperatives and promote the development of the new agricultural management subject, the cooperative union can be set up among the farmer professional cooperatives to further enhance the management strength of the farmer professional cooperatives.

For industry united organization like farmer cooperative union, "Anti-Monopoly Law" gives certain monopoly exemption. At the same time, the new agricultural management subject can cooperate with the farmers, leading enterprises, using "farmer + cooperative + company" mode of operation, it can also strengthen the cooperation with other market sales subject such as large supermarkets, thus forming a "production, supply and sale" all-in-one agricultural industry chain.

Integration of agricultural industry chain is a difficult work, involving many parts and the project is complex, more rigorous logical connection is needed. In the past, the production, sale and supply were separated from each other, and there was no communication between each part, which led to the gap, and finally led to the unbalanced development. Cooperative cooperation of farmer professional cooperatives can not only improve the production efficiency, but also enhance the overall level of agricultural production and management. It should adopt the pattern of complementation with other sales subjects, in order to make the connection between the industrial chain and the value chain of new agricultural management subject more contact. At present, we need to enhance the competitiveness of the management subject, strengthen the 
cooperation with others, to promote the sustainable development of the entire agricultural industry chain through strong taking weak cooperation mode.

Take the labor division efficiency and factor efficiency as the guide, clarify the market position of new agricultural management subject. First of all, cultivate new agricultural management subject's market awareness, to promote its accurate grasp of the entire market, and try to become bigger and stronger. Second, guarantee the new agricultural management subject has the various rights, which general market players should have, to enhance their market competitiveness. Finally, give the new agricultural management subject relevant lawsuit qualification, and let it under the protection of the law, so that it can obtain timely and effective help when the legitimate rights and interests are unlawfully infringed, and complete the policy that financially benefits farmers.

\section{Summary}

Under the situation of China's market economy system being constantly completing, the diversification development of new agricultural management subject is the inevitable trend, which resulted from the society continuous development and rapid improvement of agricultural production level, and has important impact on improving China's overall national strength, which is also the significant support for China's socialist modernization. Therefore, with the continuous promotion of information technology and network technology, according to the development needs of the current agricultural management subject, we should strengthen the effective improvement of rural land contract system, land transfer system and so on to enhance the new professional farmers' innovation awareness, management awareness, etc. And the intensity to improve and promote rural financial system should be increased, so as to truly improve the overall efficiency of China's agriculture.

\section{Acknowledgement}

This work was supported by the grants from Hubei Provincial Collaborative Innovation Centre of Agricultural E-Commerce(under Construction), (Wuhan Donghu University Research [2016] No.15 Document)

\section{References}

[1] Wang Huimin, Long Wenjun. The diversified development and system supply of the new agricultural management subject [J]. China Rural Finance, 2014,01: 25-27.

[2] Cui Ningbo, Song Xiujuan, Yu Xingye. Development constraints and recommendations on the new agricultural management subject [J]. Jiangxi Social Sciences, 2014,03: 52-57.

[3] Wang Fayuan. The comparisons of new agricultural management subject between China and foreign country and policy recommendations [J]. Agricultural economy, 2014,10: 26-32 +101.

[4] Lou Dong, Kong Xiangzhi. The diversified development and realistic view of new agricultural management subject [J]. Reform, 2013,02: 65-77.

[5] PoSiqinTana. Main characteristics analysis and development evolution of the China's new agricultural management subject [J]. Jiangsu Agricultural Sciences, 2016,02: 463-467.

[6] Yang Guo, Chen Yao. Design of incentive mechanism for new agricultural management subject to participate in the development of low-carbon agriculture [J]. China Population, Resources and Environment, 2016,06: 94-99. 